\title{
Tumor DNA hypomethylation of LINE-1 is associated with low tumor grade of breast cancer in Tunisian patients
}

\author{
HAYET RADIA ZEGGAR ${ }^{1}$, ALEXANDRE HOW-KIT ${ }^{2}$, ANTOINE DAUNAY ${ }^{2}$, \\ ILHEM BETTAIEB $^{3}$, MOURAD SAHBATOU $^{4}$, KHALED RAHAL $^{5}$, OLFA ADOUNI ${ }^{3}$, \\ AMOR GAMMOUDI $^{3}$, HAYET DOUIK ${ }^{1}$, JEAN-FRANÇOIS DELEUZE ${ }^{2,6}$ and MAHER KHARRAT ${ }^{1}$
}

\begin{abstract}
${ }^{1}$ University of Tunis El Manar, Faculty of Medicine of Tunis, LR99ES10 Human Genetics Laboratory, 1007 Tunis, Tunisia; ${ }^{2}$ Laboratoire de Génomique, Fondation Jean Dausset-CEPH, Centre d'Etude du Polymorphisme Humain, 75010 Paris, France; ${ }^{3}$ Department of Immunohistocytology, Salah Azaïz Cancer Institute, 1006 Tunis, Tunisia; ${ }^{4}$ Laboratoire de Biostatistique, Fondation Jean Dausset-CEPH, Centre d'Etude du Polymorphisme Humain, 75010 Paris, France; ${ }^{5}$ Service de Chirurgie Carcinologique, Institut Salah Azaiz de Tunis, 1006 Tunis, Tunisia; ${ }^{6}$ Centre National de Recherche en Génomique Humaine, CEA, Le Commissariat à l'énergie atomique et aux énergies alternatives-Institut François Jacob, 92265 Evry, France
\end{abstract}

Received December 26, 2019; Accepted May 19, 2020

DOI: $10.3892 / \mathrm{ol} .2020 .11745$

\begin{abstract}
DNA hypomethylation of long interspersed repetitive DNA retrotransposon (LINE-1) and Alu repeats elements of short interspersed elements family (SINEs) is an early event in carcinogenesis that causes transcriptional activation and leads to chromosomal instability. In the current study, DNA methylation levels of LINE-1 and Alu repeats were analyzed in tumoral tissues of invasive breast cancer in a Tunisian cohort and its association with the clinicopathological features of patients was defined. DNA methylation of LINE-1 and Alu repeats were analyzed using pyrosequencing in 61 invasive breast cancers. Median values observed for DNA methylation of LINE-1 and Alu repeats were considered as the cut-off (59.81 and $18.49 \%$, respectively). The results of the current study demonstrated a positive correlation between DNA methylation levels of LINE-1 and Alu repeats (rho=0.284; $\mathrm{P}<0.03$ ). DNA hypomethylation of LINE-1 was also indicated to be associated with low grade $(\mathrm{P}=0.023)$. To the best of our knowledge, the current study is the first study regarding DNA methylation of LINE-1 and Alu repeats element in breast cancer of the Tunisian population. The results of the current study suggest that, since hypomethylation of LINE-1 is associated with low grade, it could be used as a biomarker for prognosis for patients with breast cancer.
\end{abstract}

Correspondence to: Dr Maher Kharrat, University of Tunis El Manar, Faculty of Medicine of Tunis, LR99ES10 Human Genetics Laboratory, 15 Rue Djebel Lakhdar, La Rabta, 1007 Tunis, Tunisia

E-mail: maher.kharrat@fmt.utm.tn

Key words: breast cancer, DNA methylation, hypomethylation, long interspersed repetitive DNA retrotransposon, alu repeats, pyrosequencing

\section{Introduction}

Breast cancer is the most frequently diagnosed malignancy in women worldwide and the most common cause of death from cancer (1).

It is a heterogeneous disease caused by a combination of genetic, hormonal, and environmental factors. Moreover, epigenetic modifications have also been shown to be implicated in breast cancer progression. These alterations, including DNA methylation, are one of the emerging and promising research fields in human cancer (2), and are an early event in carcinogenesis and play a role as relevant as genetic mutations $(3,4)$. DNA Methylation is a post replicated reversible molecular modification consisting of the addition of a methyl group (-CH3) to the 5' cytosine of the pyrimidine ring in the CG dinucleotide sequence known as $\mathrm{CpG}$. This addition is mediated by enzymes of the DNA methyl-transferases (5). CpG dinucleotides represent $2-5 \%$ of the whole genome sequence and the majority of these sequences (60-80\%) are methylated in normal tissues $(6,7)$.

While the regional DNA hypermethylation has been well characterized in human cancer, this was not the case for the global DNA hypomethylation $(8,9)$. The latter occurs in $\mathrm{CpG}$ poor regions and repetitive elements and is associated with genomic and chromosomal instabilities leading to the activation of oncogenes. DNA hypomethylation happens in about $50 \%$ of breast cancers $(6,10)$ and correlates with histologic grade, stage and malignancy (11).

DNA repetitive elements are well represented and dispersed throughout the human genome and constitute about $50 \%$ of the human genome (12). There are two major repetitive elements sequences in the human genome. The first is the long interspersed repetitive DNA retrotransposon (LINE-1) composing about $17 \%$ of the human genome and present in over 500,000 copies. The second is the Alu repeats elements of short interspersed elements family (SINEs), composing 11\% of the human genome and present with one million copies (13). 
LINE-1 and Alu repeats are used as surrogate markers for global methylation status (14) because of their high abundance and density of CpG, $13 \%$ for LINE-1 and $23 \%$ for Alu repeats. In normal tissues, LINE-1 and Alu repeats are mostly heavily methylated. However, it has been observed that the DNA methylation levels of LINE-1 and Alu repeats could be different in some tissue types and genome locations (15-17).

In cancer cells, the hypomethylation of LINE-1 and Alu repeats have been described and associated with transcriptional enhancement $(18,19)$, which may lead to genome instability and retrotransposition of transposable elements $(20,21)$. Various studies reported that LINE-1 and Alu repeats were hypomethylated in different types of cancers such as colorectal (22), ovarian (23) and breast cancers $(24,25)$.

Moreover, it was shown that the levels of LINE-1 and Alu repeats methylation change during breast cancer progression (26) and was associated with poor prognosis, poor clinical outcomes and also with tumor progression $(20,27,28)$. The hypomethylation levels of LINE-1 and Alu repeats were observed as an early event in carcinogenesis $(29,30)$. Based on several studies, it was suggested to use the hypomethylation of LINE-1 and Alu repeats as an epigenetic cancer biomarker for cancer diagnosis and prognosis $(31,32)$.

This study aims to analyze the methylation levels of LINE-1 and Alu repeats in tumoral tissues of breast cancer using pyrosequencing in order to define the association of clinicopathological features with DNA hypomethylation in breast cancer in a cohort of Tunisian women.

\section{Materials and methods}

Study population. 61 breast cancer patients with primary invasive ductal carcinoma (IDC), who had undergone surgery between 2008 and 2010, at Salah Azeiz institute Tunis Tunisia, were enrolled in this study. Clinicopathological data were available for 60 patients and summarized in Table I. The study was approved by the Ethical Committee of Salah Azeiz Institute of Tunis and informed consent was obtained from all patients.

DNA isolation. DNA was extracted from fresh frozen tumoral tissue using DNeasy Blood and Tissue Kit (Qiagen) according to the manufacturer's instructions. The quantity, as well as the quality of the extracted DNAs, were measured using both of the Nanodrop spectrophotometers by the A260/A280 ratio (Thermo Fisher Scientific, Inc.) and the Qubit 3 fluorometer (Life Technologies).

Methylation analysis. For the current study, genomic DNA was treated with sodium bisulfite conversion using the EpiTect 96 Bisulfite kit (Qiagen) according to the manufacturer's instructions. After bisulfite conversion, PCR reaction was performed with $20 \mathrm{ng}$ of bisulfite-treated DNA in a $25 \mu \mathrm{l}$ volume reaction which contained: $2.5 \mu \mathrm{l}$ of the buffer, $1.6 \mu \mathrm{l}$ (25 mM) of Mgcl2, $1 \mu \mathrm{l}(10 \mathrm{mM})$ of dNTP, $0.2 \mu \mathrm{l}$ of HotStar Taq DNA polymerase, $1 \mu \mathrm{l}$ of bisulfite converted DNA and completing to $25 \mu \mathrm{l}$ with $\mathrm{H}_{2} \mathrm{O}$. Regarding the LINE-1 primers, $0.5 \mu \mathrm{l}(10 \mu \mathrm{M})$ forward and reverse primer were added, concerning the Alu repeats primers we used: $0.1 \mu \mathrm{l}(10 \mu \mathrm{M})$ forward primer, $1 \mu \mathrm{l}(10 \mu \mathrm{M})$ reverse primer, $0.9 \mu \mathrm{l}(10 \mu \mathrm{M})$
Table I. Clinicopathological characteristics of the cohort (61 patients).

\begin{tabular}{|c|c|}
\hline Characteristics & No. $(\%)$ \\
\hline \multicolumn{2}{|l|}{ Age } \\
\hline Mean & 52.62 \\
\hline Range & 33 to 81 \\
\hline \multicolumn{2}{|l|}{ Menopausal status } \\
\hline Premenopausal & $28(45.9)$ \\
\hline Postmenopausal & $32(52.5)$ \\
\hline Not determined & 1 \\
\hline \multicolumn{2}{|l|}{ Tumor size } \\
\hline $\mathrm{T} 1$ & $5(8.2)$ \\
\hline $\mathrm{T} 2$ & $43(70.5)$ \\
\hline T3 & 4 (6.6) \\
\hline $\mathrm{T} 4$ & $7(11.5)$ \\
\hline Not determined & $2(3.3)$ \\
\hline \multicolumn{2}{|l|}{ Nodal status } \\
\hline N0 & $10(16.4)$ \\
\hline N1 & $46(75.4)$ \\
\hline $\mathrm{N} 2$ & $3(4.9)$ \\
\hline Not determined & $2(3.3)$ \\
\hline \multicolumn{2}{|l|}{ Pathological stage } \\
\hline I & $3(4.9)$ \\
\hline II & $45(73.8)$ \\
\hline III & $11(18.0)$ \\
\hline Not determined & $2(3.3)$ \\
\hline \multicolumn{2}{|l|}{ Histologic grade } \\
\hline I & $9(14.8)$ \\
\hline II & $34(55.7)$ \\
\hline III & $16(26.2)$ \\
\hline Not determined & $2(3.3)$ \\
\hline \multicolumn{2}{|c|}{ Oestrogen receptor status } \\
\hline Negative & $20(32.8)$ \\
\hline Positive & $39(63.9)$ \\
\hline Not determined & $2(3.3)$ \\
\hline \multicolumn{2}{|c|}{ Progesteron receptor status } \\
\hline Negative & $21(34.4)$ \\
\hline Positive & $38(62.3)$ \\
\hline Not determined & $2(3.3)$ \\
\hline \multicolumn{2}{|c|}{ HER2 amplification } \\
\hline Negative & $31(50.9)$ \\
\hline Positive & $25(41)$ \\
\hline Not determined & $5(8.2)$ \\
\hline
\end{tabular}

HER2, human epidermal growth factor receptor 2.

Universal Biotin. PCR conditions were $10 \mathrm{~min}$ at $95^{\circ} \mathrm{C} ; 30 \mathrm{sec}$ at $95^{\circ} \mathrm{C}, 30 \mathrm{sec}$ at the annealing temperature (Ta), $15 \mathrm{sec}$ at $72^{\circ} \mathrm{C}$ for 50 cycles; $5 \mathrm{~min}$ at $72^{\circ} \mathrm{C}$. The Ta for LINE-1 and Alu were $60^{\circ} \mathrm{C}$ and $54^{\circ} \mathrm{C}$, respectively. The design of the sequences of the primers, listed in Table II, was based on previous studies $(25,33)$. 
Table II. Sequences of Primers used for LINE-1 and Alu repeats amplification.

\begin{tabular}{llr}
\hline Gene & \multicolumn{1}{c}{ Primer sequence 5'-3' } & Number of CpGs \\
\hline Alu & Forward: 5'-GGGACACCGCTGATCGTATATTTTTATTAAAA & 4 \\
& ATATAAAAATTAGT-3' & \\
& Reverse: 5'-CCAAACTAAAATACAATAA-3' & \\
& Universal Biotin primer: 5-Biotin-GGGACACCGCTGATCGTATA-3 \\
& Pyro primer: 5'-AATAACTAAAATTACAAAC-3' & 5 \\
LINE-1 & Forward: 5'-TTTTGAGTTAGGTGTGGGATATA-3' & \\
& Reverse: 5'-Biotin-AAAATCAAAAAATTCCCTTTC-3' & \\
& Pyro primer: 5'-GGGTGGGAGTGAT-3'
\end{tabular}

LINE-1, long interspersed repetitive DNA retrotransposon; CpG, 5'-Cytosine-phosphate-guanine-3' .

$5 \mu \mathrm{l}$ of the $\mathrm{PCR}$ reaction and no-template control were analyzed by electrophoresis on a $2 \%$ agarose gel. Pyrosequencing was performed to measure methylation levels of LINE-1 and Alu repeats. The biotinylated PCR products were bound to beads and the biotinylated strand was isolated as described in the Busato et al study (34). DNA methylation analysis was performed on a PyroMark Q96 MD (Qiagen) using PyroMark Gold SQA Q96 kit (Qiagen) according to the manufacturer's protocol. Data obtained was analyzed by PyroMark $\mathrm{CpG}$ Software, at each $\mathrm{CpG}$ site analyzed, the ratio of $\mathrm{C}$ to $\mathrm{T}$ nucleotides was calculated as a percentage for LINE-1 methylation, and the ratio of $\mathrm{G}$ to $\mathrm{A}$ was calculated as a percentage for Alu repeats methylation (20). The means methylation levels for 5 measured $\mathrm{CpG}$ sites of LINE-1 and for 4 measured $\mathrm{CpG}$ sites of Alu repeats were used for statistical analysis.

Statistical analysis. All statistical analysis were performed using the IBM SPSS Statistics for Windows software, v20 (IBM Corp.). $\mathrm{P}<0.05$ was considered to indicate a statistically significant difference.

Pearson and Spearman correlation analysis were used to determine the correlation between methylation levels of LINE-1 and Alu repeats. The cut-off used to categorize samples as methylated or hypomethylated was the median values of the DNA methylation levels of LINE-1 and Alu repeats. Chi-square and Fisher's exact test were used to evaluate the associations between LINE-1 and Alu repeats methylation status and clinicopathologic characteristics. ANOVA followed by Tukey's multiple comparison post-hoc test were used to compare the means between grades. The disease-free survival (DFS) rate was analyzed by the Kaplan-Meir method and compared using the log-rank test.

\section{Results}

The methylation levels of two repetitive elements LINE-1 and Alu repeats were analyzed to evaluate DNA hypomethylation in tumor tissue from 61 breast cancer patients. Clinicopathological data are summarized in Table I. The mean age of the patients was $\mathbf{5 2 . 6 2}$ years. Correlation analysis revealed a weak positive correlation between LINE-1 and Alu repeats DNA methylation levels (Pearson coefficient, rho $=0.284, \mathrm{P}<0.03)$, (Spearman coefficient, rho=0.341,
$\mathrm{P}=0.009$ ) (Fig. 1). We performed the correlation test between LINE-1 and Alu repeats DNA methylation levels separately in the Grade I, Grade II, and Grade III. As results we obtained that there was no correlation between line 1 and Alu in: Grade I (Pearson coefficient, rho=0.384, P=0.307), (Spearman coefficient, rho=0.391, P=0.134), Grade II (Pearson coefficient, $\mathrm{rho}=0.256, \mathrm{P}=0.164)$, (Spearman coefficient, $\mathrm{rho}=0.340$, $\mathrm{P}=0.062$ ). Grade III (Pearson coefficient, $\mathrm{rho}=0.304, \mathrm{P}=0.252$ ) (Spearman coefficient, rho=0.100, $\mathrm{P}=0.798$ ).

The distribution of the methylation levels for both LINE-1 and Alu repeats is illustrated in (Fig. 2). The median methylation level was $59.81 \%$ for LINE-1 (from 29.66 to $74.12 \%$, mean $58.12 \%$ ) and was $18.49 \%$ (from 15.75 to $24.22 \%$, mean $18.38 \%$ ) for Alu repeats. The median was considered as the cut-off for LINE-1 and Alu repeats DNA hypomethylation. The association between clinicopathological parameters and DNA methylation levels (<median vs. $>$ median) of both repetitive elements is shown in Table III. LINE-1 DNA hypomethylation was significantly associated with low grade $(\mathrm{P}=0.023)$. The median methylation level of LINE-1 in high-grade breast cancer was $62.41 \%$, while low grade was $59.08 \%$. Box plot comparing the Grade I, Grade II and Grade III according to LINE-1 methylation levels (A) and according to Alu methylation levels (B) is illustrated in the (Fig. 3). We performed the ANOVA test comparing the means between grades, obtaining a $\mathrm{p}$ value of $\mathrm{P}=0.382$. We then used Tukey's test as a post-hoc test, obtaining as results: (Grade 1-Grade 2) $\mathrm{P}=0.646$, (Grade 1-Grade 3) P=0.351, (Grade 2-Grade 3) $\mathrm{P}=0.712$. These results are not statistically significant.

Furthermore, no statistically significant associations were found for DNA hypomethylation of LINE-1 with other parameters including patient's age $(\mathrm{P}=0.215), \mathrm{T}$ stage $(\mathrm{P}=0.173)$, $\mathrm{N}$ stage $(\mathrm{P}=0.570)$, ER status $(\mathrm{P}=0.534)$ and $\mathrm{PR}$ status $(\mathrm{P}=0.579)$, HER2 status $(\mathrm{P}=0.206)$. There was no significant associations for DNA hypomethylation of Alu repeats with all clinicopathological parameters: Age $(\mathrm{P}=0.551)$, $\mathrm{T}$ stage $(\mathrm{P}=0.416) \mathrm{N}$ stage $(\mathrm{P}=0.589)$, ER status $(\mathrm{P}=0.320)$, $\mathrm{PR}$ status $(\mathrm{P}=0.231)$ HER2 status $(\mathrm{P}=0.561)$ and grade $(\mathrm{P}=0.552)$.

We analyzed patient disease-free survival curve in 45 patients by Kaplan-Meier analyses, the median follow-up time was 69,95 months (range 1.91 to 131,99 ) median was chosen as a cut-off to define LINE-1 and Alu repeats hypomethylation $(<59.81 \%,<18.49 \%)$. There were six distant 


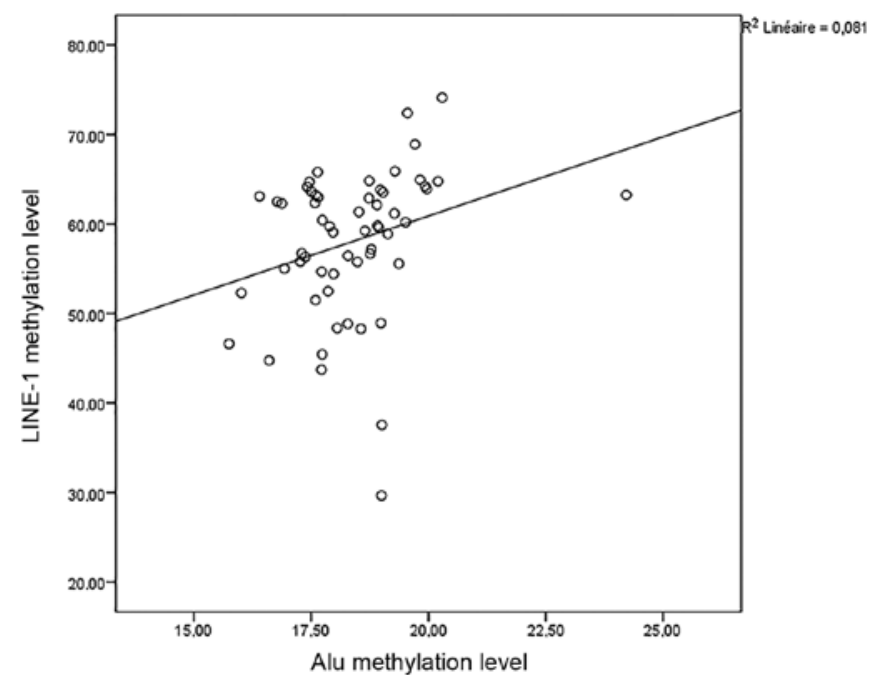

Figure 1. Scatter plot illustrating the weak positive correlation between LINE-1 and Alu DNA methylation levels (Pearson coefficient, rho=0.284; $\mathrm{P}<0.03$ ). LINE-1, long interspersed repetitive DNA retrotransposon.

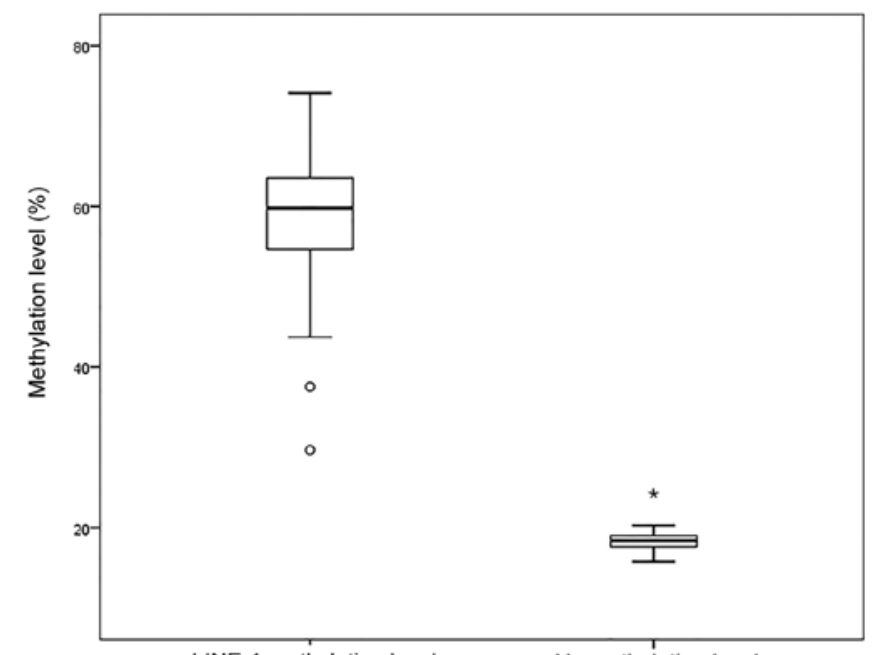

LINE-1 methylation level

Alu methylation level

Figure 2. Box plot illustrating the variation of methylation of LINE-1 (median methylation level was 59.81\%), and of Alu repeats (median methylation level was $18.49 \%$ ). LINE-1, long interspersed repetitive DNA retrotransposon.

metastases (2.7\%) and one loco-regional recurrence (0.45\%). LINE-1 and Alu repeats hypomethylation were not associated with shorter disease-free survival time (log-rank test, $\mathrm{P}=0.312$ and $\mathrm{P}=0.632$ ), respectively.

\section{Discussion}

Currently, several different classifications to determine the prognosis in breast cancer patients, based on histopathological criteria and immunohistochemistry results are used but have shown some limits due to the heterogeneous nature of the disease $(35,36)$. DNA methylation markers have been suggested as a new and promising approach for the stratification of the patients in cancer that could bear some prognosis and predictive information (37).

The purpose of our study was to evaluate the DNA methylation levels of the repetitive elements LINE-1 and Alu repeats
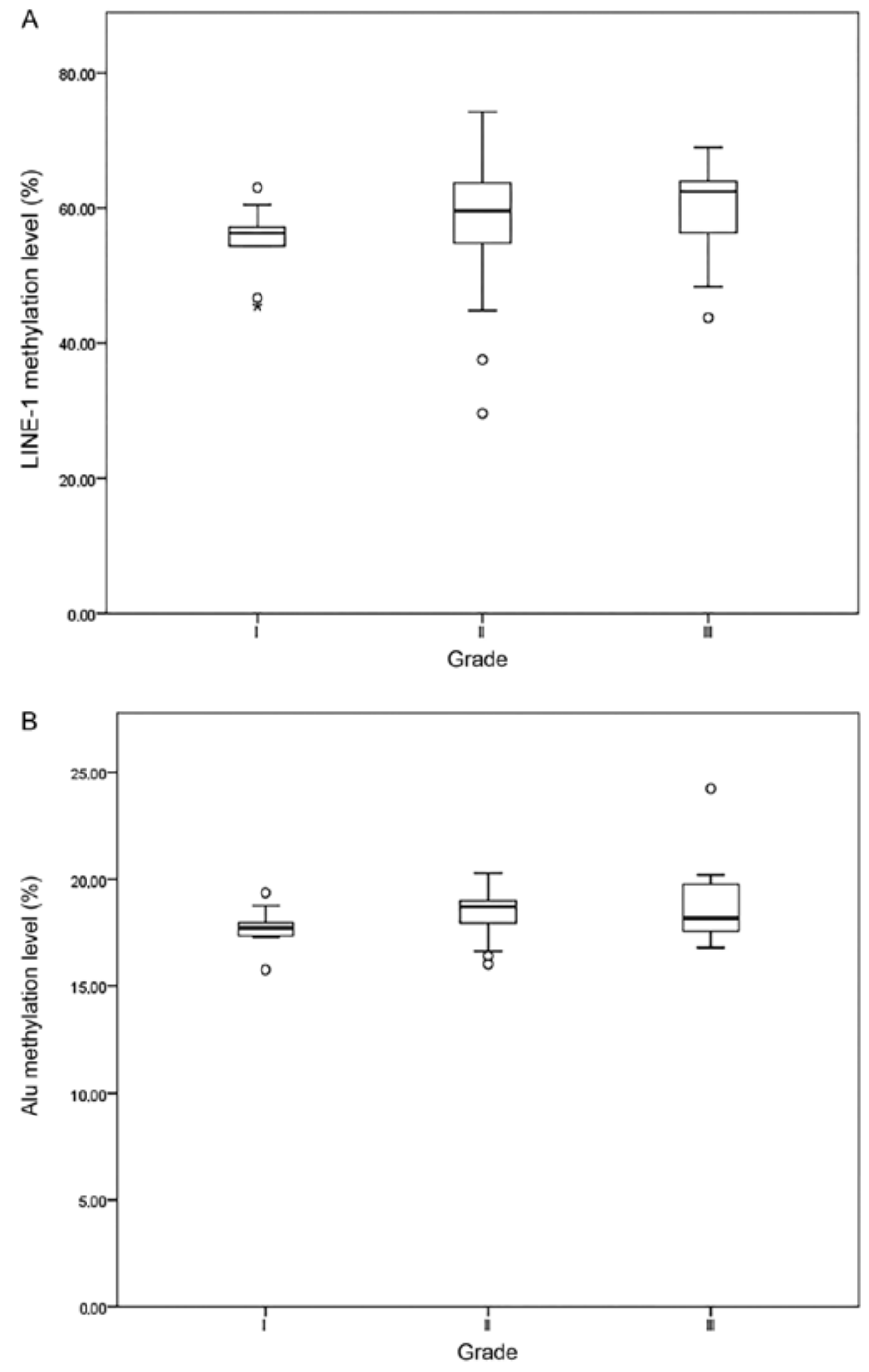

Figure 3. Box plot comparing the Grade I, Grade II and Grade III according to (A) LINE-1 methylation levels and according to (B) Alu methylation levels. LINE-1, long interspersed repetitive DNA retrotransposon.

in tumoral breast cancer cells, which were never studied in Tunisian patients and to investigate for possible associations with clinicopathological features. The measurement of DNA methylation level was performed by pyrosequencing. This sequencing-by-synthesis method stands out from other techniques by offering us a considerable advantage through the high quality and the quantitative nature of the results $(38,39)$.

LINE-1 and Alu repeats are crucial contributors to the dynamics, plasticity and integrity of the human genome (40). A previous study suggests that the hypomethylation of these repeats elements might contribute to a significant portion of the development and progression of cancer by activating them (41). This mechanism leads to recombination events and insertions (42).

In the present study, we found that methylation of LINE-1 and Alu repeats correlates positively The status of the two patients who give a very high hypomethylation of LINE according to (Fig. 1) is Grade II for both of them, which explains the low correlation between methylation levels. Since LINE-1 and Alu repeats are dispersed throughout the whole genome. They can be considered as being a surrogate marker for global 
Table III. Clinicopathological characteristics of patients according to LINE-1 and Alu methylation status of invasive breast cancer.

\begin{tabular}{|c|c|c|c|c|c|c|}
\hline Characteristic & $\begin{array}{c}\text { Alu } \\
\text { hypomethylated } \\
<\text { median } \\
(18.49 \%)\end{array}$ & $\begin{array}{c}\quad \text { Alu } \\
\text { methylated } \\
\geq \text { median } \\
(18.49 \%)\end{array}$ & P-value & $\begin{array}{c}\text { LINE-1 } \\
\text { hypomethylated } \\
<\text { median } \\
(59.81 \%)\end{array}$ & $\begin{array}{l}\text { LINE-1 } \\
\text { methylated } \\
\geq \text { median } \\
(59.81 \%)\end{array}$ & P-value \\
\hline Number (\%) & $30(50)$ & $30(50)$ & & $29(49.2)$ & $30(50.8)$ & \\
\hline Age at diagnosis (Row \%) & & & $0.551^{\mathrm{b}}$ & & & $0.215^{\mathrm{b}}$ \\
\hline$<50$ years & $13(46.43)$ & $15(53.57)$ & & $16(57.14)$ & $12(42.86)$ & \\
\hline$\geq 50$ years & $16(51.61)$ & $15(48.39)$ & & $12(40)$ & $18(60)$ & \\
\hline Not determined & 1 & - & & 2 & - & \\
\hline Tumor size (Row \%) & & & $0.416^{\mathrm{a}}$ & & & $0.173^{\mathrm{a}}$ \\
\hline $\mathrm{T} 1$ & $1(20)$ & $4(80)$ & & $1(25)$ & $3(75)$ & \\
\hline $\mathrm{T} 2$ & $22(51.16)$ & $21(48.84)$ & & $23(54.76)$ & $19(45.24)$ & \\
\hline $\mathrm{T} 3$ and $\mathrm{T} 4$ & $5(45.45)$ & $6(54.54)$ & & $3(27.27)$ & $8(72.72)$ & \\
\hline Not determined & 2 & - & & - & - & \\
\hline Nodal status (Row \%) & & & $0.589^{b}$ & & & $0.570^{\mathrm{b}}$ \\
\hline Positive & $5(50)$ & $5(50)$ & & $4(44.4)$ & $5(55.5)$ & \\
\hline Negative & $23(47.91)$ & $25(52.09)$ & & $23(47.91)$ & $25(52.08)$ & \\
\hline Not determined & 2 & - & & 1 & - & \\
\hline Pathological stage (Row \%) & & & $0.228^{\mathrm{a}}$ & & & $0.601^{\mathrm{a}}$ \\
\hline I & $0(0)$ & $3(100)$ & & $1(33.33)$ & $2(66.66)$ & \\
\hline II & $23(51.11)$ & $22(48.89)$ & & $2(51.16)$ & $21(48.84)$ & \\
\hline III & $5(50)$ & $5(50)$ & & $4(36.36)$ & $7(63.64)$ & \\
\hline Not determined & 2 & & & & & \\
\hline Histologic grade (Row \%) & & & $0.552^{\mathrm{b}}$ & & & $0.023^{\mathrm{b}}$ \\
\hline Low grade $(\mathrm{I} / \mathrm{II})$ & $20(47.62)$ & $22(52.38)$ & & $24(58.53)$ & $17(41.46)$ & \\
\hline High grade (III) & $8(50)$ & $8(50)$ & & $4(25)$ & $12(75)$ & \\
\hline Not determined & 2 & - & & - & 1 & \\
\hline ER & & & $0.320^{\mathrm{b}}$ & & & $0.534^{\mathrm{b}}$ \\
\hline Negative & $11(57.9)$ & $8(42.1)$ & & $10(50)$ & $10(50)$ & \\
\hline Positive & $18(46.15)$ & $21(53.85)$ & & $18(47.37)$ & $20(52.63)$ & \\
\hline Not determined & 1 & 1 & & 1 & - & \\
\hline $\mathrm{PR}$ & & & $0.231^{\mathrm{b}}$ & & & $0.579^{\mathrm{b}}$ \\
\hline Negative & $12(60)$ & $8(40)$ & & $10(47.62)$ & $11(52.39)$ & \\
\hline Positive & $17(44.74)$ & $21(55.26)$ & & $18(48.65)$ & $19(51.36)$ & \\
\hline Not determined & 1 & 1 & & 1 & - & \\
\hline HER2 amplification & & & $0.561^{\mathrm{b}}$ & & & $0.206^{\mathrm{b}}$ \\
\hline Negative & $15(48.39)$ & $16(51.61)$ & & $17(56.66)$ & $13(43.33)$ & \\
\hline Positive & $12(50)$ & $12(50)$ & & $10(41.66)$ & $14(58.33)$ & \\
\hline Not determined & 3 & 2 & & 2 & 3 & \\
\hline
\end{tabular}

${ }^{a} \chi^{2}$ test; ${ }^{b}$ Fisher's exact test; ER, Oestrogen receptor status; PR, progesterone receptor status; LINE-1, long interspersed repetitive DNA retrotransposon.

methylation status. Moreover, Ross et al (43) reported in their study that repeats elements hypomethylation, as well as demethylation of single-copy genes, are mechanistically linked and might be mediated by the same factors. Thus, we suggest that some oncogenes may also be hypomethylated in our cohort.

Furthermore, based on several previous studies on various types of tissues, we applied the median value as a cut-off for the methylation levels (hypomethylated vs. methylated) for both LINE-1 and Alu repeats. Our median value was similar to large scale studies values $(20,26,44)$. The median value of our cohort for Alu repeats was $18.49 \%$. Previous studies suggested that the cut-off median for Alu repeats were $20.2 \%$ in breast cancer. The median value for LINE-1 was $59.81 \%$ which was close to the selected cut-off median for LINE-1 
$59.4 \%$ in breast cancer in former studies (26). We observed a great variation of LINE-1 methylation levels, which is concordant with the literature (26). Furthermore, unlike LINE-1, we observed the stability of Alu methylation levels. Moreover, the methylation levels of repeated elements are relative to the elements by themselves. Therefore, a relatively low methylation of LINE-1 should be considered as hypomethylation even though it is superior to the Alu median level of methylation.

Moreover, it was reported that, in several carcinomas such as breast and colon cancer, there is a great difference in methylation levels of LINE-1 and Alu repeats between tumoral tissues and their adjacent normal tissues $(28,45,46)$. Previous studies have shown that DNA methylation levels of LINE-1 were from 70 to $90 \%$ in normal tissues $(47,48)$, and were from 55 to $60 \%$ in tumor tissues. These results suggest that patients with cancer could be characterized by global hypomethylation (49,50). Regarding Alu repeats methylation levels, it was reported that in normal somatic tissue, this element was highly methylated $(51,52)$. In cancer tissues, earlier studies have shown that the level of hypomethylation of Alu repeats was different among cancer types. In breast cancer, there is a lower level of hypomethylation than in colon and lung cancer, which exhibited a higher level of hypomethylation (30).

Our results showed that the hypomethylation of LINE-1 was associated with low-grade tumors, while it has been suggested that DNA mutations are associated with high-grade tumors. The mechanism by which LINE-1 hypomethylation affects tumor grade remains unclear. We could suggest that the LINE-1 hypomethylation, which leads to chromosomal instability (49), might represent one of the possible mechanisms. On the other hand, the antisense promoter of LINE-1 can activate the gene expression of surrounding genes (53), which might have been involved in tumor grading; this could also be a hypothesis explaining the mechanism. Given that LINE-1 hypomethylation is associated with low grade, it could be considered as a good prognostic marker. In that way, methylation analysis is not superior to histologic studies, but it should be used in combination with histologic analysis.

Moreover, no statistically significant associations were found for hypomethylation of LINE-1 with clinicopathological features ER, PR, HER2 status, age, T stage and $\mathrm{N}$ stage. Regarding the hypomethylation of Alu, no statistically significant associations were found with all clinicopathological features. Different results were obtained in various studies of breast cancer. For example, Park et al (26) showed that hypomethylation of LINE-1 was associated with negative ER status, negative PR status, and positive HER2 status. However, Alu repeats hypomethylation was only associated with ER negativity. van Hoesel et al (24), reported that in breast cancer, LINE-1 hypomethylation was associated with tumor stage, nodal status and age. Cho et al (54) showed that LINE-1 hypomethylation was statistically associated with premenopausal women, whereas the methylation level of Alu repeats was not associated with any clinical outcome.

The relationship between overall survival or disease-free survival and DNA hypomethylation of LINE-1 and Alu repeats have been analyzed in various studies in human cancer $(20,55)$. In the present study, LINE-1 and Alu repeats hypomethylation were not associated with shorter disease-free survival. Park et al (26) reported that LINE-1 hypomethylation was also not associated with disease evolution, whereas Alu hypomethylation tended to be associated with poor disease-free survival, van Hoesel et al (24) reported that in young breast cancer patients ( $\leq 55$ years), LINE-1 hypomethylation was associated with a bad prognosis.

It seemed difficult to compare results from several studies since they were based on different sample sizes varying from small to a large cohort. Several low throughput methods AQAMA PCR assay (24), Methylight (54), pyrosequencing (56), have been developed and used in studies for the analysis of DNA methylation. However, none of them appeared to be the 'gold-standard' technique that combines high sensitivity, quantitative accuracy and cost-effectiveness. In various studies, several experimental designs were proposed, different consensus sequences were chosen to analyze DNA methylation levels of repetitive elements, without reaching a common experimental design. Moreover, there was no optimal consensual cut-off. Park et al (26) applied the median value as a cut-off, whereas van Hoesel et al (24) used the 25th percentile of methylation levels to define the hypomethylated group; other studies were based on a qualitative method to identify the presence of methylation.

The limitation of our study is the number of methylated samples. Nevertheless, considering the small size of the Tunisian population (11.78 millions), our cohort of 61 patients could be considered informative to determine a decrease of methylation frequency of LINE-1 and Alu repeats.

Based on the results of several studies, it was suggested to use LINE-1 as a surrogate marker for global methylation status and potentials biomarker for negative prognostic and breast cancer risk $(24,57)$. In this first study regarding DNA methylation of LINE-1 and Alu repeats element in breast cancer of the Tunisian population, our results showed a positive correlation between DNA methylation levels of LINE-1 and Alu repeats. Regarding association with clinical features, DNA hypomethylation of LINE-1 was associated with low grade, which suggests that LINE-1 hypomethylation could be used as a biomarker for good prognostic.

\section{Acknowledgements}

Not applicable.

\section{Funding}

No funding was received.

\section{Availability of data and materials}

The datasets used and/or analyzed during the present study are available from the corresponding author on reasonable request.

\section{Authors' contributions}

HRZ, AH, HD, JFD and MK designed the experiments. HRZ performed experiments and wrote the original draft. HRZ, AH and AD analyzed data. IB, OA and AG performed immunohistological investigation. KR performed clinical investigation. HRZ and MS performed statistical analysis of the data. AH and MK performed validation of the study, and 
reviewed and edited the final manuscript. All authors read and approved the final manuscript.

\section{Ethics approval and consent to participate}

The study was approved by the Ethical Committee of Salah Azeiz Institute of Tunis. Informed consent was obtained from all patients.

\section{Patient consent for publication}

Informed consent was obtained from all patients.

\section{Competing interests}

The authors declare that they have no competing interests.

\section{References}

1. Ferlay J, Colombet M, Soerjomataram I, Mathers C, Parkin DM, Piñeros M, Znaor A and Bray F: Estimating the global cancer incidence and mortality in 2018: GLOBOCAN sources and methods. Int J Cancer 144: 1941-1953, 2019.

2. Baba Y, Yagi T, Sawayama H, Hiyoshi Y, Ishimoto T, Iwatsuki M, Miyamoto Y, Yoshida N and Baba H: Long interspersed element-1 methylation level as a prognostic biomarker in gastrointestinal cancers. Digestion 97: 26-30, 2018.

3. Stefansson OA and Esteller M: Epigenetic modifications in breast cancer and their role in personalized medicine. Am J Pathol 183: 1052-1063, 2013.

4. Baxter E, Windloch K, Gannon F and Lee JS: Epigenetic regulation in cancer progression. Cell Biosci 4: 45, 2014.

5. Bird A: DNA methylation patterns and epigenetic memory. Genes Dev 16: 6-21, 2002.

6. Atalay C: Epigenetics in breast cancer. Exp Oncol 35: 246-249, 2013.

7. Andersen GB and Tost J: A summary of the biological processes, disease-associated changes, and clinical applications of DNA methylation. Methods Mol Biol 1708: 3-30, 2018.

8. Baylin SB, Esteller M, Rountree MR, Bachman KE, Schuebel K and Herman JG: Aberrant patterns of DNA methylation, chromatin formation and gene expression in cancer. Hum Mol Genet 10: 687-692, 2001.

9. Ehrlich M: DNA methylation in cancer: Too much, but also too little. Oncogene 21: 5400-5413, 2002.

10. Ye D, Jiang D, Li Y, Jin M and Chen K: The role of LINE-1 methylation in predicting survival among colorectal cancer patients: A meta-analysis. Int J Clin Oncol 22: 749-757, 2017.

11. Szyf M, Pakneshan P and Rabbani SA: DNA methylation and breast cancer. Biochem Pharmacol 68: 1187-1197, 2004.

12. Zheng Y, Joyce BT, Liu L, Zhang Z, Kibbe WA, Zhang W and Hou L: Prediction of genome-wide DNA methylation in repetitive elements. Nucleic Acids Res 45: 8697-8711, 2017.

13. Lander ES, Linton LM, Birren B, Nusbaum C, Zody MC Baldwin J, Devon K, Dewar K, Doyle M, FitzHugh W, et al: Initial sequencing and analysis of the human genome. Nature 409: 860-921, 2001.

14. Luo Y, Lu X and Xie H: Dynamic Alu methylation during normal development, aging, and tumorigenesis. Biomed Res Int 2014: 784706, 2014.

15. Xie H, Wang M, Bonaldo Mde F, Smith C, Rajaram V, Goldman S, Tomita $\mathrm{T}$ and Soares MB: High-throughput sequence-based epigenomic analysis of Alu repeats in human cerebellum. Nucleic Acids Res 37: 4331-4340, 2009.

16. Schmid CW: Human Alu subfamilies and their methylation revealed by blot hybridization. Nucleic Acids Res 19: 5613-5617, 1991.

17. Phokaew C, Kowudtitham S, Subbalekha K, Shuangshoti S and Mutirangura A: LINE-1 methylation patterns of different loci in normal and cancerous cells. Nucleic Acids Res 36: 5704-5712, 2008

18. Yoder JA, Walsh CP and Bestor TH: Cytosine methylation and the ecology of intragenomic parasites. Trends Genet 13: 335-340, 1997.

19. Hoffmann MJ and Schulz WA: Causes and consequences of DNA hypomethylation in human cancer. Biochem Cell Biol 83: 296-321, 2005
20. Bae JM, Shin SH, Kwon HJ, Park SY, Kook MC, Kim YW, Cho NY, Kim N, Kim TY, Kim D and Kang GH: ALU and LINE-1 hypomethylations in multistep gastric carcinogenesis and their prognostic implications. Int J Cancer 131: 1323-1331, 2012.

21. Saito K, Kawakami K, Matsumoto I, Oda M, Watanabe G and Minamoto T: Long interspersed nuclear element 1 hypomethylation is a marker of poor prognosis in stage IA non-small cell lung cancer. Clin Cancer Res 16: 2418-2426, 2010.

22. Antelo M, Balaguer F, Shia J, Shen Y, Hur K, Moreira L, Cuatrecasas M, Bujanda L, Giraldez MD, Takahashi M, et al: A high degree of LINE-1 hypomethylation is a unique feature of early-onset colorectal cancer. PLoS One 7: e45357, 2012.

23. Dammann RH, Kirsch S, Schagdarsurengin U, Dansranjavin T, Gradhand E, Schmitt WD and Hauptmann S: Frequent aberrant methylation of the imprinted IGF2/H19 locus and LINE1 hypomethylation in ovarian carcinoma. Int J Oncol 36: 171-179, 2010.

24. van Hoesel AQ, van de Velde CJ, Kuppen PJ, Liefers GJ, Putter H, Sato Y, Elashoff DA, Turner RR, Shamonki JM, de Kruijf EM, et al: Hypomethylation of LINE-1 in primary tumor has poor prognosis in young breast cancer patients: A retrospective cohort study. Breast Cancer Res Treat 134: 1103-1114, 2012.

25. Choi IS, Estecio MR, Nagano Y, Kim DH, White JA, Yao JC, Issa JPJ and Rashid A: Hypomethylation of LINE-1 and Alu in well-differentiated neuroendocrine tumors (pancreatic endocrine tumors and carcinoid tumors). Mod Pathol 20: 802-810, 2007.

26. Park SY, Seo AN, Jung HY, Gwak JM, Jung N, Cho NY and Kang GH: Alu and LINE-1 hypomethylation is associated with HER2 enriched subtype of breast cancer. PLoS One 9: e100429, 2014.

27. Bakshi A, Herke SW, Batzer MA and Kim J: DNA methylation variation of human-specific Alu repeats. Epigenetics 11: 163-173, 2016.

28. Cho NY, Kim BH, Choi M, Yoo EJ, Moon KC, Cho YM, Kim D and Kang GH: Hypermethylation of $\mathrm{CpG}$ island loci and hypomethylation of LINE-1 and Alu repeats in prostate adenocarcinoma and their relationship to clinicopathological features. J Pathol 211: 269-277, 2007.

29. Kwon HJ, Kim JH, Bae JM, Cho NY, Kim TY and Kang GH: DNA methylation changes in ex-adenoma carcinoma of the large intestine. Virchows Arch 457: 433-441, 2010.

30. Chalitchagorn K, Shuangshoti S, Hourpai N, Kongruttanachok N, Tangkijvanich P, Thong-ngam D, Voravud N, Sriuranpong V and Mutirangura A: Distinctive pattern of LINE-1 methylation level in normal tissues and the association with carcinogenesis. Oncogene 23: 8841-8846, 2004.

31. Shigaki H, Baba Y, Watanabe M, Murata A, Iwagami S, Miyake K, Ishimoto T, Iwatsuki $M$ and Baba H: LINE-1 hypomethylation in gastric cancer, detected by bisulfite pyrosequencing, is associated with poor prognosis. Gastric Cancer 16: 480-487, 2013.

32. Khakpour G, Pooladi A, Izadi P, Noruzinia M and Tavakkoly Bazzaz J: DNA methylation as a promising landscape: A simple blood test for breast cancer prediction. Tumour Biol 36: 4905-4912, 2015.

33. Wong JY, De Vivo I, Lin X, Grashow R, Cavallari J and Christiani DC: The association between global DNA methylation and telomere length in a longitudinal study of boilermakers. Genet Epidemiol 38: 254-264, 2014.

34. Busato F, Dejeux E, El Abdalaoui H, Gut IG and Tost J: Quantitative DNA methylation analysis at single-nucleotide resolution by pyrosequencing(R). Methods Mol Biol 1708: 427-445, 2018.

35. Matsumoto A, Jinno H, Ando T, Fujii T, Nakamura T, Saito J, Takahashi M, Hayashida T and Kitagawa Y: Biological markers of invasive breast cancer. Jpn J Clin Oncol 46: 99-105, 2016.

36. Malhotra GK, Zhao X, Band $\mathrm{H}$ and Band V: Histological, molecular and functional subtypes of breast cancers. Cancer Biol Ther 10: 955-960, 2010.

37. Levenson VV: DNA methylation as a universal biomarker. Expert Rev Mol Diagn 10: 481-488, 2010.

38. Ronaghi M: Pyrosequencing sheds light on DNA sequencing. Genome Res 11: 3-11, 2001.

39. Tost J and Gut IG: DNA methylation analysis by pyrosequencing. Nat Protoc 2: 2265-2275, 2007.

40. Erichsen L, Beermann A, Arauzo-Bravo MJ, Hassan M, Dkhil MA, Al-Quraishy S, Hafiz TA, Fischer JC and Santourlidis S: Genome-wide hypomethylation of LINE-1 and Alu retroelements in cell-free DNA of blood is an epigenetic biomarker of human aging. Saudi J Biol Sci 25: 1220-1226, 2018. 
41. Hancks DC and Kazazian HH Jr: Roles for retrotransposon insertions in human disease. Mob DNA 7: 9, 2016.

42. Deininger PL and Batzer MA: Alu repeats and human disease. Mol Genet Metab 67: 183-193, 1999.

43. Ross JP, Rand KN and Molloy PL: Hypomethylation of repeated DNA sequences in cancer. Epigenomics 2: 245-269, 2010.

44. Kuan TC, Lin PC, Yang SH, Lin CC, Lan YT, Lin HH, Liang WY, Chen WS, Lin JK, Jiang JK and Chang SC: Impact of LINE-1 hypomethylation on the clinicopathological and molecular features of colorectal cancer patients. PLoS One 13: e0197681, 2018.

45. Estecio MR, Gharibyan V, Shen L, Ibrahim AEK, Doshi K, He R, Jelinek J, Yang AS, Yan PS, Huang THM, et al: LINE-1 hypomethylation in cancer is highly variable and inversely correlated with microsatellite instability. PLoS One 2: e399, 2007.

46. Woraruthai T, Charoenlap C, Hongsaprabhas C, Mutirangura A and Honsawek S: Alu hypermethylation and high oxidative stress in patients with musculoskeletal tumors. PeerJ 6: e5492, 2018.

47. Michels KB, Harris HR and Barault L: Birthweight, maternal weight trajectories and global DNA methylation of LINE-1 repetitive elements. PLoS One 6: e25254, 2011.

48. Kupcinskas J, Steponaitiene R, Langner C, Smailyte G Skieceviciene J, Kupcinskas L, Malfertheiner P and Link A: LINE-1 hypomethylation is not a common event in preneoplastic stages of gastric carcinogenesis. Sci Rep 7: 4828, 2017.

49. Ogino S, Kawasaki T, Nosho K, Ohnishi M, Suemoto Y, Kirkner GJ and Fuchs CS: LINE-1 hypomethylation is inversely associated with microsatellite instability and $\mathrm{CpG}$ island methylator phenotype in colorectal cancer. Int J Cancer 122: 2767-2773, 2008 .
50. Schernhammer ES, Giovannucci E, Kawasaki T, Rosner B, Fuchs CS and Ogino S: Dietary folate, alcohol and B vitamins in relation to LINE-1 hypomethylation in colon cancer. Gut 59: 794-799, 2010.

51. Sigurdsson MI, Smith AV, Bjornsson HT and Jonsson JJ: Distribution of a marker of germline methylation differs between major families of transposon-derived repeats in the human genome. Gene 492: 104-109, 2012.

52. Kochanek S, Renz D and Doerfler W: DNA methylation in the alu sequences of diploid and haploid primary human cells. EMBO J 12: 1141-1151, 1993.

53. Weber B, Kimhi S, Howard G, Eden A and Lyko F: Demethylation of a LINE-1 antisense promoter in the cMet locus impairs Met signalling through induction of illegitimate transcription. Oncogene 29: 5775-5784, 2010

54. Cho YH, Yazici H, Wu HC, Terry MB, Gonzalez K, Qu M, Dalay N and Santella RM: Aberrant promoter hypermethylation and genomic hypomethylation in tumor, adjacent normal tissues and blood from breast cancer patients. Anticancer Res 30: 2489-2496, 2010.

55. Chen J, Huan W, Zuo H, Zhao L, Huang C, Liu X, Hou S, Qi J and Shi W: Alu methylation serves as a biomarker for non-invasive diagnosis of glioma. Oncotarget 7: 26099-26106, 2016.

56. Wu HC, Delgado-Cruzata L, Flom JD, Perrin M, Liao Y, Ferris JS, Santella RM and Terry MB: Repetitive element DNA methylation levels in white blood cell DNA from sisters discordant for breast cancer from the New York site of the breast cancer family registry. Carcinogenesis 33: 1946-1952, 2012.

57. Cao X, Holland-Letz T, Tang Q, Li X, Gündert M, Cuk K, Schott S, Heil J, Golatta M and Sohn C: Investigation of global methylation in peripheral blood from breast cancer patients. J Mol Biomark Diagn: doi:10.4172/2155-9929.S2-037. 